\title{
Daily physical activity, human development index and insomnia in a representative sample of Brazilian adolescents: a cross-sectional analysis
}

Antônio Evaldo dos Santos', Raphael Henrique de Oliveira Araujo", Josiene Oliveira Couto"', Danilo Rodrigues Pereira da Silvalv, Roberto Jerônimo dos Santos Silvav

Department of Physical Education, Universidade Federal de Sergipe (UFS), São Cristóvão (SE), Brazil

'MSc. Physical Education Professional, Department of Physical Education, Universidade Federal de Sergipe (UFS), São Cristóvão (SE), Brazil.

(D) https://orcid.org/0000-0001-8837-0329

"MSc. Physical Education Professional,

Department of Physical Education, Universidade Federal de Sergipe (UFS), São Cristóvão (SE), Brazil.

(D) https://orcid.org/0000-0002-9405-3052

'"MSc. Physical Education Professional, Department of Physical Education, Universidade Federal de Sergipe (UFS), São Cristóvão (SE), Brazil.

(D) https://orcid.org/0000-0002-1328-6859

"vphD. Physical Education Professional, Department of Physical Education, Universidade Federal de Sergipe (UFS), São Cristóvão (SE), Brazil.

(D) https://orcid.org/0000-0003-3995-4795

vphD. Physical Education Professional, Department of Physical Education, Universidade Federal de Sergipe (UFS), São Cristóvão (SE), Brazil.

(D) https://orcid.org/0000-0002-4578-7666

KEY WORDS (MeSH terms):

Exercise.

Sleep initiation and maintenance disorders. Sleep.

Adolescent.

Mental health.

\section{AUTHORS' KEY WORDS:}

Physical activity.

Insomnia.

Sleep habits.

Youth.

\begin{abstract}
BACKGROUND: Although there is a growing body of research pointing towards the need to investigate how different movement behaviors, such as physical activity and sleep, influence each other, the joint relationship between these factors and insomnia has been little explored among adolescents in developing countries.

OBJECTIVES: To investigate the association between daily physical activity and insomnia in a national sample of Brazilian adolescents, according to the Human Development Index (HDI) of each Brazilian region.

DESIGN AND SETTINGS: Cross-sectional study on 102,072 Brazilian students aged 11 to 19 years, selected from all regions of the country.

METHODS: Information on insomnia and physical activity was self-reported by adolescents.

RESULTS: Our analyses revealed that girls who accumulated at least 60 minutes/day of physical activity on up to three days/week were less prone to present insomnia. This pattern of association was maintained only for those who lived in high HDI regions (odds ratio, 0.87 ; $95 \%$ confidence interval, 0.75-0.99). For boys, there was a positive association between the number of active days and protection against insomnia, especially for those who lived in high HDI regions.

CONCLUSION: Even amounts of physical activity that were lower than the weekly guidelines, were associated with better sleep quality for Brazilian adolescents, especially girls, and even for those who lived in regions with greater social and economic vulnerability.
\end{abstract}

\section{INTRODUCTION}

Insomnia is defined as persistent difficulty in falling asleep and staying asleep, despite adequate sleep opportunities, ${ }^{1}$ and is considered to be the most common sleep disorder during adolescence, with an estimated prevalence ranging from $6 \%$ to $30 \%$ in this age group. ${ }^{1}$ Previous research has shown that insomnia is associated with symptoms of depression, substance abuse, poor school performance, mood disorders, ${ }^{2,3}$ social withdrawal and loneliness, ${ }^{4}$ lower emotional regulation, ${ }^{5,6}$ anxiety and suicidal thoughts. ${ }^{7}$ Despite the recommendations that adolescents should sleep for 8 to 10 hours per day, ${ }^{8}$ few young people achieve sufficient amounts of sleep, ${ }^{9}$ which converges on a secular trend of reduced sleep duration among children and adolescents. ${ }^{10}$ This scenario highlights insomnia as an important public health issue, as well as demonstrating the need to establish effective and suitable ways to address this problem during adolescence.

In this regard, the scientific literature provides arguments for different strategies for treating insomnia, such as cognitive-behavioral therapy and pharmacotherapy. ${ }^{11,12}$ However, although similar efficacy has been demonstrated between these therapies for treating insomnia, ${ }^{13}$ both of them are difficult to apply on a large scale, especially in the context of developing countries. ${ }^{14}$ Thus, studies have pointed towards physical activity (PA) as a possible low-cost strategy for reducing the effects of insomnia among adolescents. ${ }^{15}$ In a meta-analysis on 12 studies that investigated the relationship between PA and sleep among adolescents, it was concluded that individuals with higher PA levels, assessed subjectively and objectively, were more likely to present better sleep quality.$^{16}$ Furthermore, the results from a clinical review demonstrated that moderate aerobic exercise training could be prescribed as pertinent non-pharmacological treatment for sleep 
disorders. ${ }^{17}$ Likewise, cross-sectional data from a survey of 14,782 American adolescents showed that only those who were active for at least 60 minutes/day, every day, presented an association with sufficient amounts of sleep ( $\geq 8$ hours of sleep per night on an average school night). ${ }^{18}$ However, that analysis was not stratified by sex, which may have limited the interpretation of the results, since boys and girls differ in their PA levels and sleep quality. ${ }^{19}$

In addition, although research has shown that higher total PA levels are associated with better sleep quality, ${ }^{16,18,20}$ this relationship remains unclear. Studies carried out among adolescents in 33 European countries ${ }^{21}$ and in $\mathrm{Canada}^{22} \mathrm{did}$ not find any association between higher PA levels and sleep disorders. Complementing these findings, the results from a longitudinal study on adolescents indicated that changes to accumulation of physical activity were unrelated to changes in mental health outcomes, such as mental distress, ${ }^{23}$ although the latter can be a confounder between physical activity and sleep disorders. However, considering the social and economic differences between developed and developing countries, there is a lack of information on how this association occurs among Brazilian adolescents, considering that the prevalence of PA varies according to a country's level of development. ${ }^{24}$

Furthermore, a growing body of research has also pointed towards the need to investigate how different movement behaviors over a 24-hour period, such as PA, sedentary behavior (SB) and sleep, influence each other. ${ }^{25}$ Likewise, there is evidence that points towards the existence of a relationship between health-related behaviors, such as PA, SB and sleep, and urban and socioeconomic development. ${ }^{26}$ Previous research has shown that the features of both the social environment (family, social cohesion, safety, noise and socioeconomic status) and the physical environment (light exposure, traffic, air pollution and walkability) may influence sleep. ${ }^{27,28}$ However, the joint relationship between these factors and insomnia has not been explored.

\section{OBJECTIVES}

The objectives of the present study were: 1) to investigate the association between daily PA and insomnia, in a national sample of Brazilian adolescents; and 2) to verify whether this association varies according to sex and the HDI of the region of this country.

\section{METHODS}

\section{Study design and sample}

This was a cross-sectional analysis based on data from the National School-based Health Survey (PeNSE in Portuguese), conducted in Brazil between April and September 2015. This survey had the aim of assessing the risk and protective factors relating to the health of students enrolled in public and private schools throughout Brazil. ${ }^{29}$ The sampling process and methods are detailed elsewhere. ${ }^{29}$ Briefly, PeNSE 2015 was the third edition of this survey, with previous editions conducted in 2009 and 2012. Unlike the other editions, the PeNSE 2015 database was composed of two different samples, named: sample 1, which included students in the $9^{\text {th }}$ grade of elementary school; and sample 2, composed of students aged 13 to 17 years, from the $6^{\text {th }}$ grade of elementary school up to the $3^{\text {rd }}$ grade of high school, in the reference year of this study. ${ }^{29}$ This analysis focuses on sample 1 , due to the greater representativeness of these data on the students' health.

For sample 1, students were selected through a complex cluster sampling process, which included schools in the 26 state capitals, plus the Federal District and 26 other municipalities, resulting in a total of 53 strata. In the capitals, the sampling process was carried out in two stages (schools as primary units and classes as secondary units), while in the other municipalities, stratification involved three stages (municipalities as primary units, schools as secondary units and classes as tertiary units). The sample size was calculated for each stratum, considering a sampling error of $3 \%$, prevalence of $50 \%$ and confidence interval of $95 \%{ }^{29}$

Data were collected through a self-administered electronic questionnaire, composed of two main sections. The first section related to the school's characteristics and was filled out by the principal or coordinator. The second section was self-administered by students and assessed their individual characteristics. Based on the 2013 school census, 3160 schools were selected and invited to participate in the study, totaling 4159 classes. All students in the classes selected were invited. In total, 3040 public and private schools, with 124,227 students, were considered eligible to participate in the study. Among the students present on the day of data collection, 102,301 (82\%) agreed to participate in the study. ${ }^{29}$ Because of missing data, the current analysis considered data from 102,072 students ( $51.7 \%$ girls) aged from 11 to 19 years (mean age of $14.33 \pm 1.06$ years).

Informed consent was obtained from parents/legal guardians, and student assent was also obtained, as required by local ethics review boards. All procedures of PeNSE 2015 were approved by the National Research Ethics Committee of the National Health Council, and the study was conducted in accordance with the principles expressed in the Declaration of Helsinki (CONEP no. 1.006.467; dated March 30, 2015).

\section{Insomnia}

The prevalence of insomnia was obtained through self-reports, by means of the following question: "In the past 12 months, how often have you been unable to sleep at night because something worried you a lot?" The response options were "Never", "Rarely", "Sometimes", "Most of the time" or "Always". The first three options were categorized as "No" = "0". Individuals who 
answered "Most of the time" or "Always" were classified as having insomnia and were categorized as "Yes" = " 1 ". This categorization procedure was also used in a previous study. ${ }^{20}$

\section{Physical activity}

Daily physical activity was self-reported through a validated questionnaire, ${ }^{30}$ using the following question: "In the past seven days, on how many days did you exercise for at least 60 minutes a day?" Daily physical activity was categorized according to the number of days reported (zero to seven).

\section{Geographical regions}

The analyses were stratified according to the Human Development Index (HDI) of Brazil's five macroregions. Thus, the Brazilian regions were classified as having low HDI (North $=0.667$; Northeast $=0.663$ ) = "0"; or as having high HDI (Southeast $=0.766$; CenterWest $=0.757$; South $=0.754)=$ " 1 " ${ }^{31}$ This form of classification is used in studies on regional inequalities in Brazil. ${ }^{32}$

\section{Covariables}

The following covariables were considered: a) age group ( $<14$ years or $\geq 14$ years); b) ethnicity, which in the present study was dichotomized as "white" or "non-white" (black, Asian, brown/mixed or indigenous); c) bullying, obtained through the question: "Have you ever been bullied?", with the answer options "yes" or "no". Those who answered "yes" were considered to be victims of bullying and were categorized as "1"; and d) television viewing, which was self-reported through the item: "On an ordinary weekday, how many hours per day do you watch TV? (do not consider Saturday, Sunday or holidays)". The response options ranged from "I don't watch TV" to "More than 8 hours per day" and the answers were categorized as " $\leq 2$ hours", " $>2$ to $\leq 4$ hours" or " $>4$ hours".

\section{Statistical analysis}

Descriptive statistics were presented as absolute and relative frequencies, stratified according to sex, along with confidence intervals (95\% CI). Crude and adjusted binary logistic regression models, stratified according to sex and HDI of the Brazilian regions, were constructed in order to estimate the odds ratio (OR) and $95 \%$ CI. Only covariates with a P-value $<0.2$ in the crude analyses were included in the final model. The statistical analyses were performed using the Statistical Package for the Social Sciences (SPSS) software, version 22.0 (IBM, Armonk, New York, United States), with statistical significance taken to be $\mathrm{P} \leq 0.05$.

\section{RESULTS}

The descriptive characteristics of the sample according to sex are shown in Table 1. A total of 102,072 students (51.7\% girls) participated in the study, with a mean age of $14.33 \pm 1.06$ years (ranging from 11 to 19 years), and most of them were "nonwhite" (> 65\%). Almost $60 \%$ of the adolescents were from regions with low HDI. A greater proportion of the girls reported that they had been victims of bullying. Approximately one third of the adolescents reported watching TV for more than four hours per day. The prevalence of insomnia was more than twice as high for the girls (15.6\%), compared with the boys. The proportion of the boys (13.4\%) who declared that they had been active for at least 60 minutes/day, in the seven days prior to the survey, was three times higher than the proportion of the girls (4.3\%).

In the crude and adjusted associations between daily PA and insomnia, according to sex and HDI of the Brazilian regions (Table 2), it was observed that, compared with their most inactive peers (zero/no active day), girls who accumulated at least 60 minutes/day of physical activity on up to three days/week were less prone to present insomnia, regardless of the region's HDI. After adjusting the analyses, this pattern of association was maintained only for those who lived in high HDI regions ( $O R=0.87 ; 95 \%$ $\mathrm{CI}=0.75-0.99)$. On the other hand, girls who accumulated at least 60 minutes/day of physical activity on seven days presented higher odds of insomnia, even after adjusting the analyses and regardless of the region's HDI (low HDI: OR = 1.17; 95\% CI = 1.01-1.35; high HDI: $\mathrm{OR}=1.25 ; 95 \% \mathrm{CI}=1.05-1.48)$. Among the boys, there was a positive association between the number of active days and protection against insomnia, especially for those who lived in high HDI regions.

\section{DISCUSSION}

The findings of the present study demonstrated that girls who were active for at least 60 minutes/day, on up to two days/week (low HDI) and on up to three days/week (high HDI) presented lower odds of insomnia. However, girls who achieved the daily guidelines for PA on all days presented greater odds of insomnia (regardless of the region's HDI). For boys, there was a positive association between the number of active days and protection against insomnia, mainly for those who lived in regions with high HDI.

Compared with their most inactive peers (no active day), girls who were active for at least two days/week and boys who were active for at least five days/week presented lower odds of insomnia. These results were similar to previous research conducted among adolescents, which found that higher levels of PA were associated with better sleep quality. ${ }^{16,17,20}$ However, we found that this association varied according to the number of active days/week and according to the HDI of the region, which suggested that for this group of schoolchildren the association between PA and sleep did not depend on achievement of the international PA guidelines. This is especially important since previous research had 
Table 1. Descriptive characteristics of the sample according to sex $(n=102,072)$

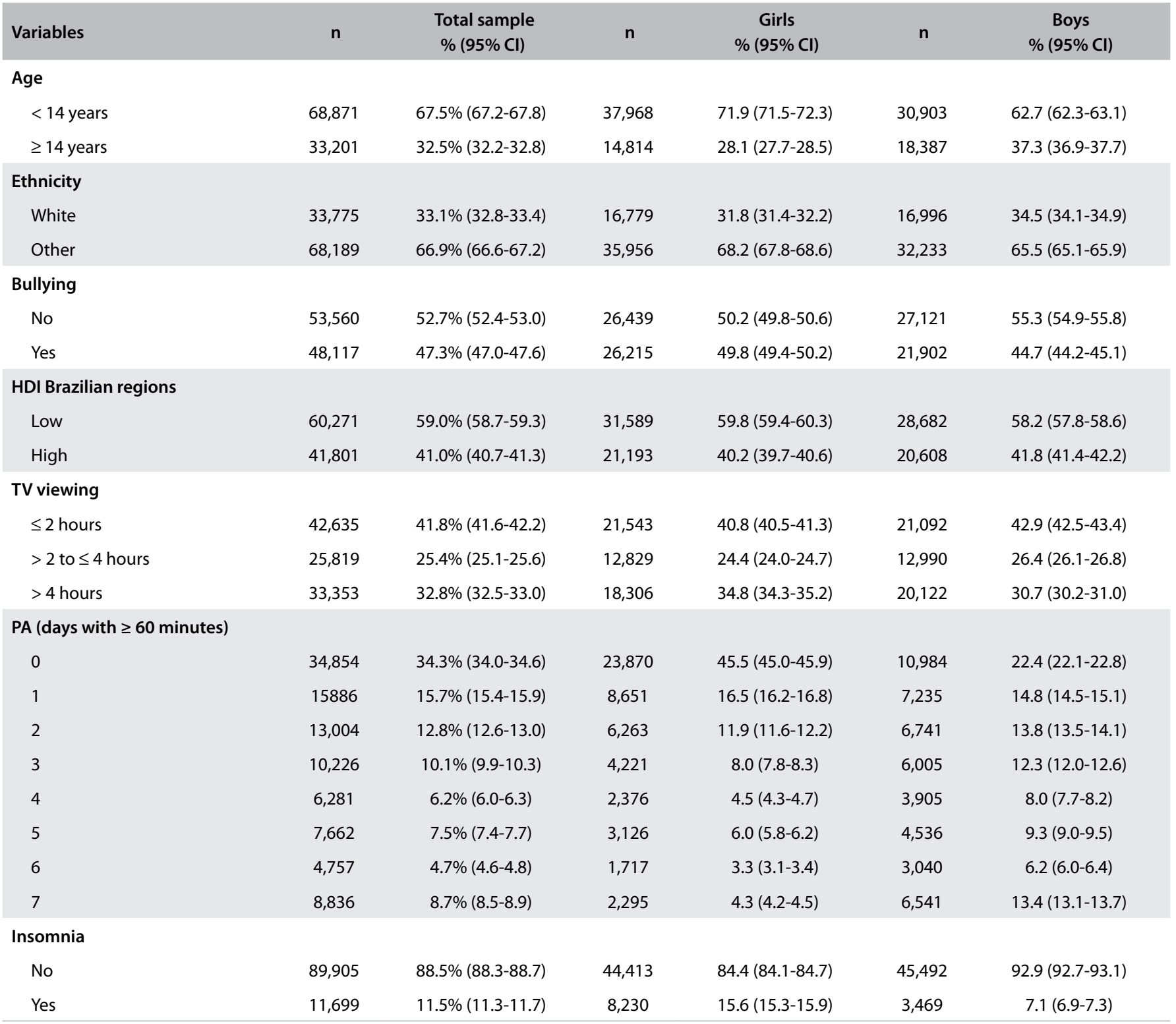

$\mathrm{Cl}=$ confidence interval; $\mathrm{HDI}=$ Human Development Index; $\mathrm{PA}=$ physical activity.

suggested that although the dose-response relationship between PA and mental health outcomes was uncertain, it could occur even at lower doses. ${ }^{33-35}$ Likewise, a study conducted with a representative sample of European adolescents suggested that even those who did not reach the international PA recommendations, but who showed moderately increased activity, could achieve a meaningful improvement in wellbeing, ${ }^{36}$ which might extend to better sleep quality.

Furthermore, studies that investigated the association between socioeconomic status and sleep quality among adolescents showed that individuals who lived in regions with greater social and economic vulnerability slept less than those who lived in more developed areas. ${ }^{37-39}$ Thus, the present study has added important information regarding the impact of daily PA on the sleep quality of adolescents, suggesting that social and economic vulnerability may influence not only differences in PA recommendations, but also the association between PA and sleep.

The association between PA and sleep is based on mechanisms such as thermoregulation; increased metabolic rate and energy consumption; changes to heart rate, physical fitness levels and body composition; ${ }^{15}$ and changes to the circadian cycle. ${ }^{40}$ Furthermore, PA is associated with reduced anxiety and depression, 
Table 2. Crude and adjusted associations between daily PA ( $\geq 60$ minutes) and insomnia, according to sex and HDI of the Brazilian regions $(n=102,072)$

\begin{tabular}{|c|c|c|c|c|}
\hline \multirow{2}{*}{ Variables } & \multicolumn{4}{|c|}{ Girls } \\
\hline & Crude OR $(95 \% \mathrm{Cl})$ & Adjusted OR $(95 \% \mathrm{Cl})$ & Crude OR (95\% Cl) & Adjusted OR (95\% Cl) \\
\hline \multicolumn{5}{|c|}{ PA (days with $\geq 60$ minutes) } \\
\hline 0 & 1 & 1 & 1 & 1 \\
\hline 1 & $0.84(0.77-0.92)$ & $0.86(0.78-0.94)$ & $0.73(0.65-0.82)$ & $0.74(0.66-0.83)$ \\
\hline 3 & $0.88(0.78-1.00)$ & $0.90(0.79-1.02)$ & $0.85(0.74-0.98)$ & $0.87(0.75-0.99)$ \\
\hline 4 & $1.12(0.96-1.30)$ & $1.12(0.97-1.31)$ & $0.97(0.82-1.15)$ & $0.99(0.83-1.18)$ \\
\hline 5 & $0.93(0.81-1.07)$ & $0.93(0.81-1.07)$ & $0.95(0.81-1.11)$ & $0.96(0.82-1.12)$ \\
\hline 6 & $1.15(0.97-1.36)$ & $1.13(0.96-1.34)$ & $1.01(0.83-1.24)$ & $0.98(0.80-1.21)$ \\
\hline \multicolumn{5}{|c|}{ PA (days with $\geq 60$ minutes) } \\
\hline 0 & 1 & 1 & 1 & 1 \\
\hline 1 & $0.73(0.63-0.85)$ & $0.76(0.66-0.88)$ & $0.69(0.57-0.83)$ & $0.71(0.59-0.86)$ \\
\hline 2 & $0.70(0.60-0.82)$ & $0.74(0.64-0.87)$ & $0.58(0.47-0.70)$ & $0.61(0.50-0.74)$ \\
\hline 3 & $0.68(0.57-0.80)$ & $0.72(0.61-0.85)$ & $0.70(0.58-0.84)$ & $0.73(0.60-0.89)$ \\
\hline 4 & $0.74(0.61-0.89)$ & $0.77(0.63-0.93)$ & $0.76(0.62-0.94)$ & $0.82(0.66-1.01)$ \\
\hline 5 & $0.77(0.65-0.92)$ & $0.80(0.67-0.96)$ & $0.69(0.56-0.85)$ & $0.73(0.59-0.91)$ \\
\hline 6 & $0.81(0.66-0.99)$ & $0.83(0.68-1.02)$ & $0.75(0.59-0.95)$ & $0.78(0.61-0.99)$ \\
\hline
\end{tabular}

$\mathrm{HDI}=$ Human Development Index; $\mathrm{OR}=$ odds ratio; $\mathrm{Cl}=$ confidence interval; $\mathrm{PA}=$ physical activity.

Analysis adjusted for age group, ethnicity, bullying and TV viewing.

increased self-esteem and increased psychological wellbeing, which, in turn, may mediate the relationship between PA and sleep. ${ }^{40}$

Cross-sectional data from a previous survey carried out in the United States showed that only adolescents who were active for $\geq$ 60 minutes/day, on seven days per week, reported having sufficient amounts of sleep. ${ }^{18}$ On the other hand, we observed that even adolescents who did not reach the weekly PA guidelines, ${ }^{41}$ but who were active on at least two days/week (girls) and five days/week (boys), had better sleep quality, as also pointed out in other research. ${ }^{15,19}$ In addition, our results reinforce the differences in the association between PA and insomnia according to sex, thus corroborating previous findings, ${ }^{16,19}$ as well as highlighting the importance of planning tailored interventions that take into account the impact of social and economic vulnerabilities on health outcomes.

One interesting finding was that girls who were active for at least 60 minutes/day, on seven days per week, presented greater odds of insomnia, regardless of the HDI of the region in which they lived. This result is similar to that of previous studies, ${ }^{20,36}$ in which it was concluded that the subgroup of girls with high PA levels might include adolescents who over-exercise and who are more susceptible to stressors, such as depression symptoms and anxiety, ${ }^{36}$ which are associated with insomnia. Furthermore, an association among girls between over-exercise and sleep disorders has been documented among elite athletes, ${ }^{42,43}$ such that a high training load was associated with higher prevalence of insomnia, compared with male athletes. ${ }^{43}$

Unfortunately, the PeNSE 2015 data did not allow investigation of the influence of potential mediators, such as social and physical environmental features, like noise and air pollution, traffic, light exposure and safety, which can mediate the relationship between PA and sleep quality. ${ }^{27,28}$ Furthermore, the association among girls between over-exercise and insomnia occurred regardless of the region's HDI, and persisted even after controlling for possible confounding variables such as age, ethnicity, bullying and TV viewing, thus suggesting that other mediators that were not evaluated through PeNSE 2015 may be involved. Future research 
should investigate other possible mediators between excessive PA and insomnia, especially among girls.

Despite the relevance of the results highlighted here, the present study had some limitations. First, the data analyzed were based on questionnaires, which are more subject to recall bias. Nevertheless, questionnaires are viable low-cost instruments and have become well established in epidemiological research worldwide. ${ }^{44}$ Second, subjective sleep assessment did not allow analysis of other sleep outcomes, such as bedtime, sleep onset latency, waking time after sleep onset and total sleep time, or their possible associations with PA. ${ }^{15}$ Third, the dichotomization of the study variables may have attenuated the power to detect associations. ${ }^{45}$

However, the study also had some strengths. First, this was one of the few studies to analyze the association between daily PA and insomnia among adolescents who were not living in developed countries, and it also took social and economic vulnerability into consideration. Second, given that this survey was based on a sample with national representation, the results can be generalized for the Brazilian population of school-age adolescents. ${ }^{46}$

\section{CONCLUSION}

Even amounts of physical activity that were lower than the weekly guidelines were associated with better sleep quality for Brazilian adolescents, especially girls, and even for those who were living in regions with greater social and economic vulnerability. Thus, the present study has important implications for policy makers. It highlights the need to consider regional inequalities and it shows that physical activity-based interventions can be targeted as a lowcost, non-pharmacological and widely viable alternative that may foster better sleep quality among adolescents. Further research should encourage use of prospective data to better understand the relationship between daily physical activity and sleep quality, taking into account the influence of social and economic vulnerability.

\section{REFERENCES}

1. Roth T. Insomnia: definition, prevalence, etiology, and consequences. J Clin Sleep Med. 2007;3(5 Suppl):S7-10. PMID: 17824495.

2. Carskadon MA. Sleep in adolescents: the perfect storm. Pediatr Clin North Am. 2011;58(3):637-47. PMID: 21600346; https://doi.org/10.1016/j. pcl.2011.03.003.

3. Kaneita Y, Ohida T, Osaki Y, et al. Association between mental health status and sleep status among adolescents in Japan: a nationwide cross-sectional survey. J Clin Psychiatry. 2007;68(9):1426-35. PMID: 17915984; https://doi.org/10.4088/jcp.v68n0916.

4. Ben Simon E, Walker MP. Sleep loss causes social withdrawal and Ioneliness. Nat Commun. 2018;14;9(1):3146. PMID: 30108218; https:// doi.org/10.1038/s41467-018-05377-0.

5. Brand S, Kirov R, Kalak N, et al. Perfectionism related to self-reported insomnia severity, but not when controlled for stress and emotion regulation. Neuropsychiatr Dis Treat. 2015;11:263-71. PMID: 25678791; https://doi.org/10.2147/NDT.S74905.

6. Brand S, Kirov R, Kalak N, et al. Poor Sleep Is Related to Lower Emotional Competence Among Adolescents. Behav Sleep Med. 2016;14(6):602-14. PMID: 26507446; https://doi.org/10.1080/15402002.2015.1048450.

7. Roberts RE, Duong HT. Is there an association between short sleep duration and adolescent anxiety disorders? Sleep Med. 2017;30:82-7. PMID: 28215269; https://doi.org/10.1016/j.sleep.2016.02.007.

8. Hirshkowitz M, Whiton K, Albert SM, et al. National sleep foundation's sleep time duration recommendations: Methodology and results summary. Sleep Heal. 2015;1(1):40-3. PMID: 29073412; https://doi. org/10.1016/j.sleh.2014.12.010.

9. Owens J, Au R, Carskadon M, et al. Insufficient sleep in adolescents and young adults: An update on causes and consequences. Pediatrics. 2014;134(3):e921-32. PMID: 25157012; https://doi.org/10.1542/ peds.2014-1696.

10. Matricciani L, Olds T, Petkov J. In search of lost sleep: Secular trends in the sleep time of school-aged children and adolescents. Sleep Med Rev. 2012;16(3):203-11. PMID: 21612957; https://doi.org/10.1016/j. smrv.2011.03.005

11. Ringdahl EN, Pereira SL, Delzell JE. Treatment of primary insomnia. J Am Board Fam Pract. 2004;17(3):212-9. PMID: 15226287; https://doi. org/10.3122/jabfm.17.3.212.

12. Zakiei A, Khazaie H, Rostampour M, et al. Acceptance and Commitment Therapy (ACT) Improves Sleep Quality, Experiential Avoidance, and Emotion Regulation in Individuals with Insomnia-Results from a Randomized Interventional Study. Life. 2021;11(2):133. PMID: 33572330; https://doi.org/10.3390/life11020133.

13. Smith MT, Perlis ML, Park A, et al. Comparative meta-analysis of pharmacotherapy and behavior therapy for persistent insomnia. Am J Psychiatry. 2002;159(1):5-11. PMID: 11772681; https://doi.org/10.1176/ appi.ajp.159.1.5

14. Morin CM, Benca R. Chronic insomnia. Lancet. 2012;379(9821):1129-41. PMID: 22265700; https://doi.org/10.1016/S0140-6736(11)60750-2.

15. Kredlow MA, Capozzoli MC, Hearon BA, Calkins AW, Otto MW. The effects of physical activity on sleep: a meta-analytic review. J Behav Med. 2015;38(3):427-9. PMID: 25596964; https://doi.org/10.1007/s10865015-9617-6.

16. Lang C, Kalak N, Brand S, et al. The relationship between physical activity and sleep from mid adolescence to early adulthood. A systematic review of methodological approaches and meta-analysis. Sleep Med Rev. 2016;28:32-45. PMID: 26447947; https://doi.org/10.1016/j. smrv.2015.07.004

17. Chennaoui M, Arnal PJ, Sauvet F, Léger D. Sleep and exercise: A reciprocal issue? Sleep Med Rev. 2015;20:59-72. PMID: 25127157; https://doi. org/10.1016/j.smrv.2014.06.008.

18. Foti KE, Eaton DK, Lowry R, McKnight-Ely LR. Sufficient Sleep, Physical Activity, and Sedentary Behaviors. Am J Prev Med. 2011;41 (6):596-602. PMID: 22099236; https://doi.org/10.1016/j.amepre.2011.08.009. 
19. Brand S, Kalak N, Gerber M, et al. During early to mid-adolescence, moderate to vigorous physical activity is associated with restoring sleep, psychological functioning, mental toughness and male gender. J Sports Sci. 2017;35(5):426-34. PMID: 27033183; https://doi.org/10.10 80/02640414.2016.1167936.

20. Werneck AO, Vancampfort D, Oyeyemi AL, Stubbs B, Silva DR. Associations between TV viewing, sitting time, physical activity and insomnia among 100,839 Brazilian adolescents. Psychiatry Res. 2018;269:700-6. PMID: 30273895; https://doi.org/10.1016/j.psychres.2018.08.101.

21. Ghekiere A, Van Cauwenberg J, Vandendriessche A, et al. Trends in sleeping difficulties among European adolescents: Are these associated with physical inactivity and excessive screen time? Int J Public Health. 2019;64(4):487-98. PMID: 30535677; https://doi.org/10.1007/s00038018-1188-1.

22. Kakinami L, O'Loughlin EK, Brunet J, et al. Associations between physical activity and sedentary behavior with sleep quality and quantity in young adults. Sleep Heal. 2017;3(1):56-61. PMID: 28346152; https:// doi.org/10.1016/j.sleh.2016.11.001.

23. Opdal IM, Morseth B, Handegård BH, et al. Change in physical activity is not associated with change in mental distress among adolescents: the Troms $\varnothing$ study: Fit Futures. BMC Public Health. 2019;19(1):916. PMID: 31288796; https://doi.org/10.1186/s12889-019-7271-6.

24. Guthold R, Stevens GA, Riley LM, Bull FC. Global trends in insufficient physical activity among adolescents: a pooled analysis of 298 population-based surveys with 1.6 million participants. Lancet Child Adolesc Health. 2020;4(1):23-35. PMID: 31761562; https://doi. org/10.1016/S2352-4642(19)30323-2.

25. Chaput JP, Carson V, Gray CE, Tremblay MS. Importance of all movement behaviors in a 24 hour period for overall health. Int J Environ Res Public Health. 2014;11(12):12575-81. PMID: 25485978; https://doi.org/10.3390/ ijerph111212575.

26. Sallis JF, Cerin E, Conway TL, et al. Physical activity in relation to urban environments in 14 cities worldwide: A cross-sectional study. Lancet. 2016;387(10034):2207-17. PMID: 27045735; https://doi.org/10.1016/ S0140-6736(15)01284-2.

27. Hunter JC, Hayden KM. The association of sleep with neighborhood physical and social environment. Public Health. 2018;162(336):126-34. PMID: 30036811 ; https://doi.org/10.1016/j.puhe.2018.05.003.

28. Johnson DA, Hirsch JA, Moore KA, Redline S, Diez Roux AV. Associations between the Built Environment and Objective Measures of Sleep. Am J Epidemiol. 2018;187(5):941-50. PMID: 29547912; https://doi. org/10.1016/j.healthplace.2015.09.005.

29. Instituto Brasileiro de Geografia e Estatística (IBGE). Instituto Brasileiro de Geografia e Estatística, Pesquisa Nacional de Saúde do Escolar (PeNSE) 2015. Rio de Janeiro: IBGE; 2016.

30. Tavares LF, Castro IR, Cardoso LO, Levy RB, Claro RM, Oliveira AF. Validade de indicadores de atividade física e comportamento sedentário da Pesquisa Nacional de Saúde do Escolar entre adolescentes do Rio de Janeiro, Brasil [Validity of indicators on physical activity and sedentary behavior from the Brazilian National School-Based Health Survey among adolescents in Rio de Janeiro, Brazil]. Cad Saude Publica. 2014;30(9):1861-74. PMID: 25317515; https://doi.org/10.1590/0102$311 \times 00151913$.

31. Desenvolvimento humano nas macrorregiões brasileiras: 2016. Brasília: PNUD: IPEA: FJP; 2016. Available from: https://www.br.undp.org/ content/brazil/pt/home/library/idh/Atlas/macro-regioes-brasileiras. html. Accessed in 2021 (Apr 20).

32. Szwarcwald CL, Souza Júnior PR, Marques AP, Almeida WD, Montilla DE. Inequalities in healthy life expectancy by Brazilian geographic regions: findings from the National Health Survey, 2013. Int J Equity Health. 2016;15(1):141. PMID: 27852270; https://doi.org/10.1186/s12939-0160432-7.

33. Kline $C E$, Sui $X$, Hall MH, et al. Dose-response effects of exercise training on the subjective sleep quality of postmenopausal women: exploratory analyses of a randomised controlled trial. BMJ Open. 2012;2(4):e001044. PMID: 22798253; https://doi.org/10.1136/bmjopen-2012-001044.

34. Teychenne M, White RL, Richards J, et al. Do we need physical activity guidelines for mental health: What does the evidence tell us? Ment Health Phys Act. 2020;18:100315. https://doi.org/10.1016/j. mhpa.2019.100315.

35. Chekroud SR, Gueorguieva R, Zheutlin AB, et al. Association between physical exercise and mental health in 1.2 million individuals in the USA between 2011 and 2015: a cross-sectional study. The Lancet Psychiatry [Internet]. 2018;5(9):739-46. PMID: 30099000; https://doi.org/10.1016/ S2215-0366(18)30227-X.

36. McMahon EM, Corcoran P, O'Regan G, et al. Physical activity in European adolescents and associations with anxiety, depression and well-being Eur Child Adolesc Psychiatry. 2017;26(1):1 11-22.PMID: 27277894; https:// doi.org/10.1007/s00787-016-0875-9.

37. Bøe T, Hysing M, Stormark KM, Lundervold AJ, Sivertsen B. Sleep problems as a mediator of the association between parental education levels, perceived family economy and poor mental health in children. J Psychosom Res. 2012;73(6):430-6. PMID: 23148810; https://doi. org/10.1016/j.jpsychores.2012.09.008

38. Felden ÉPG, Leite CR, Rebelatto CF, Andrade RD, Beltrame TS. Sleep in adolescents of different socioeconomic status: A systematic review. Rev Paul Pediatr. 2014;33(4):467-73. PMID: 26298657; https://doi. org/10.1016/j.rpped.2015.01.011.

39. Perales F, Plage S. Losing ground, losing sleep: Local economic conditions, economic vulnerability, and sleep. Soc Sci Res. 2017;62:189203. PMID: 28126098; https://doi.org/10.1016/j.ssresearch.2016.08.006.

40. Youngstedt SD. Effects of exercise on sleep. Clin Sports Med. 2005;24(2):355-65. PMID: 15892929; https://doi.org/10.1016/j. csm.2004.12.003.

41. World Health Organization. Global recommendations on physical activity for health. Geneva: World Health Organization; 2010. Available from: https://www.who.int/publications/i/item/9789241599979. Accessed in 2021 (Apr 20). 
42. Dumortier J, Mariman A, Boone J, et al. Sleep, training load and performance in elite female gymnasts. Eur J Sport Sci. 2018;18(2):15161. PMID: 29072537; https://doi.org/10.1080/17461391.2017.1389992.

43. Gupta L, Morgan K, Gilchrist S. Does Elite Sport Degrade Sleep Quality? A Systematic Review. Sport Med. 2017;47(7):1317-33. PMID: 27900583; https://doi.org/10.1007/s40279-016-0650-6.

44. Sallis JF, Saelens BE. Assessment of Physical Activity by Self-Report: Status, Limitations, and Future Directions. Res Q Exerc Sport. 2000;71(sup2):1-14. PMID: 10925819; https://doi.org/10.1080/0270 1367.2000.11082780

45. MacCallum RC, Zhang S, Preacher KJ, Rucker DD. On the practice of dichotomization of quantitative variables. Psychol Methods. 2002;7(1):19-40. PMID: 11928888; https://doi.org/10.1037/1082989x.7.1.19.

46. Oliveira MM, Campos MO, Andreazzi MAR, Malta DC. Characteristics of the National Adolescent School-based Health Survey - PeNSE, Brazil. Epidemiol Serv Saude. 2017;26(3):605-16. PMID: 28977184; https://doi. org/10.5123/s1679-497420170000300017.

Authors' contributions: AES and RHOA: Literature search, study design, data analysis, and writing. JOC: Literature search, study design and review of the first draft. DRPS: Data analysis, writing and final review. RJSS: Literature search, study design, data analysis and final review. All authors actively contributed to discussion of the results from the study, and reviewed and approved the final version to be released

Sources of funding: This study was financed in part by the Coordenação de Aperfeiçoamento de Pessoal de Nível Superior (CAPES), under finance code 001

Conflicts of interest: The author(s) declare that they did not have any potential conflicts of interest with regard to the research, authorship and/or publication of this article

Date of first submission: January 12, 2021

Last received: March 23, 2021

Accepted: April 5, 2021

\section{Address for correspondence:}

Antônio Evaldo dos Santos

Programa de Pós-Graduação em Educação Física, Departamento de Educação Física, Universidade Federal de Sergipe (UFS)

Av. Marechal Rondon, s/no

São Cristóvão (SE) - Brasil

CEP 49100-000

E-mail: antoniohand13@gmail.com 